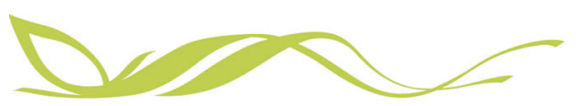

COMMUNICATIONS

EARTH\&ENMRONMENT

ARTICLE

A) Check for updates

\title{
https://doi.org/10.1038/s43247-020-00034-1 OPEN
}

\section{Distinct response of gross primary productivity in five terrestrial biomes to precipitation variability}

François Ritter ${ }^{1 凶}$, Max Berkelhammer $\mathbb{1 0}^{1 凶} \&$ Cynthia Garcia-Eidell ${ }^{1}$

Climate change will impact precipitation variability, potentially accelerating climate-terrestrial carbon feedbacks. However, the response of ecosystems to precipitation variability is difficult to constrain due to myriad physiological and abiotic variables that limit terrestrial productivity. Based on a combination of satellite imagery and a global network of daily precipitation data, we present here a statistical framework to isolate the impact of precipitation variability on the gross primary productivity of five biomes that collectively account for $50 \%$ of global land area. The productivity of mesic grasslands and forests decreases by $\sim 28 \%$ and $\sim 7 \%$ (respectively) in response to more irregular rain within the year, while the sensitivity is halved in response to higher year-to-year variability. Xeric grasslands are similarly impacted by intra-annual rainfall variance, but they show an increase in productivity with higher interannual rainfall variability. Conversely, the productivity of boreal forests increases under higher variability on both timescales. We conclude that projected changes in precipitation variability will have a measurable global impact on the terrestrial carbon sink.

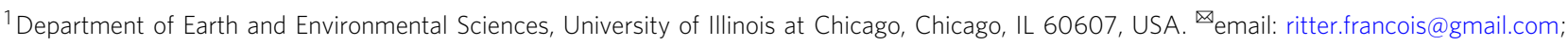
berkelha@uic.edu
} 
ong-term mean precipitation has shown a remarkable stationarity over the historical record despite warming ${ }^{1}$. However, climate models predict that precipitation variability is expected to be more impacted by climate change ${ }^{2-4}$, with evidence of these changes now emerging from observations ${ }^{5-8}$. Given that water availability is a major limiting factor for most biomes ${ }^{9}$, changes in rainfall patterns (such as less frequent but more intense storms) can have dramatic consequences on ecosystem composition and productivity ${ }^{10}$. Earlier studies have investigated the relationship between rain variability and plant productivity through three main approaches: (i) rainfall manipulation plots (or RaMPs), where rainwater is collected before it reaches the canopy and then redistributed with fewer but larger events $^{11}$; (ii) land-atmosphere models fed with different precipitation patterns to simulate the vegetation growth response $\mathrm{e}^{12}$; and, (iii) selection of several sites along a precipitation gradient to analyze how rain variability influences their productivity without altering the surrounding environment ${ }^{13,14}$. The first two approaches mainly focus on how rain frequency affects the soil moisture and, consequently, productivity while ignoring other ecological mechanisms related to rain frequency, such as leaf wetting ${ }^{15}$ or vapor pressure deficit ${ }^{16}$ that are, by design, discarded in RaMPs due to the absence of control on air moisture and are poorly captured in models due to their coarse grid size. To generate a more holistic estimate of the effects of rain frequency on productivity, we have developed here a variant of the third approach that establishes a global constraint on how productivity is affected by rainfall variance by comparing the productivity between ecosystems with similar mean climate states but different rain variability.

One of the challenges in generalizing the response of a biome to rainfall variance emerges from the diversity of ecophysiological characteristics (canopy height, rooting depth, and stomatal response to soil moisture), soil types (nutrient pool, porosity, and conductivity) and mean climate state that modulate the sensitivity of ecosystems to precipitation patterns. Consequently, former studies have produced diverging results ${ }^{17,18}$ on responses to both intra-annual (precipitation frequency and intensity within the year) and interannual variability (alternation of pluvial and drought years). For example, larger but less frequent events can have a negative $e^{13,19}$ or positive ${ }^{20}$ impact depending on the ecosystem type. Similarly, more extreme wet and dry years reduce the productivity of grasslands ${ }^{21}$ or, conversely, enhance the resilience of tropical ecosystems by forcing the development of more diverse hydraulic systems ${ }^{22}$. Studies agree that higher rain variability is more likely to benefit xeric over mesic habitats $^{12,17,21,23}$, but the overall direction and magnitude of change in terrestrial productivity due to rain variability have never been estimated empirically at a scale larger than isolated plots.

This study quantifies the long-term (2001-2018) contribution of intra-annual and interannual precipitation variability to the productivity of five biomes distributed over four continents (Fig. 1). To achieve this, we address the following issues that have limited previous studies:

(i) Rainfall is a stochastic process with high spatial and temporal variability and its variance has been quantified with numerous metrics ${ }^{6-8,12}$. Thus far, existing literature has not established a set of agreed-upon rainfall variability parameters (RVP) that are globally relevant for ecosystem productivity and can be aggregated and scaled spatially and temporally.

(ii) As described earlier, plant growth is affected by many variables: mean precipitation and mean temperature (first order drivers), plant and soil type, but also fire frequency or grazing patterns. A new statistical method is required to isolate the influence of rainfall variability on productivity from these confounding variables.

The first issue is associated with the well-known "coarsegraining problem", where information is lost through spatial and temporal averaging 24 . Weather stations with daily precipitation are therefore more appropriate than gridded (i.e., mechanistic, geospatial modeled, or remotely-sensed) precipitation data products of precipitation that do not retain the full spectrum of information on rain variability ${ }^{25}$. Using daily rainfall with continuous records back to 2001, we calculated four RVPs per station: one on the interannual scale and three on the intra-annual scale (Fig. 2a, b). While the RVPs are correlated with one another (Supplementary Fig. 7), they each emphasize the effects of specific ecological mechanisms. The coefficient of variation $(\mathrm{CV})$ is connected to ecosystem resilience to drought years ${ }^{21}$, the fraction of dry days $\left(f_{\text {dry }}\right)$ is correlated to droughts and absence of cloud cover $^{2}$ and the rain intensity $(\alpha)$ affects the mean infiltration depth $^{12}$. We also introduce a new rain frequency metric, the Unranked-Gini index (UGi), which is unitless and describes how irregularly distributed the annual precipitation amount is, spanning 0 (rainfall is equally distributed every day) to 1 (rainfall is concentrated the first or last day of the year). This new metric is more holistic compared to existing rain frequency indices because it accounts for the distribution of rain events which we hypothesized in the study design to have a critical influence on the productivity of different biomes (Supplementary Fig. 6).

The second issue has driven experimental designs that focus on individual plots where confounding factors, such as different soil types, can be disregarded. However, when aggregated, these isolated studies on the plot scale have given rise to a broad range of inconsistent results that justify the need for a global estimate of the impact of rainfall variability. We first created five biomes based on their land cover type (grasslands or forests, with croplands excluded) and their long-term mean temperature $(T)$ and precipitation $(P)$ aggregated from the daily weather stations present within $0.5^{\circ} \times 0.5^{\circ}$ grid cells (Fig. 1a, b). These biomes are associated with generic names (e.g., warm forests or cold grasslands) because they represent different ecological communities sharing similar canopy height that have been pooled to increase the sample size (Supplementary Table 1). While Net Primary Production has been the more traditional metric to study the influence on rainfall variance on ecosystems, we chose to base our analysis on the response of Gross Primary Production (GPP) because advanced estimates through combined satellite data and in situ measurements are readily available, and changes in photosynthesis can be linked directly to the response of stomatal conductance to soil moisture and vapor pressure deficit without also needing to consider the response of respiration. Three stateof-the-art global GPP products were utilized in this study: SATFLUX $^{26}$, FLUXCOM RS + METEO $^{27}$ (hereafter, simply FLUXCOM) and the Vegetation Photosynthesis Model or VPM ${ }^{28}$. To isolate the impact of each RVP (UGi, $\alpha, f_{\text {dry }}$, or CV) on the GPP of a biome, a new statistical approach was developed which we refer to as the pairing method (example in Fig. 2c). The mean precipitation, temperature and biome type are set as fixed variables within a selected pair of grid cells, and we compare two populations of pairs, control (RVP is fixed) and experiment (RVP is varying), to detect how each RVP influences GPP across the population of all paired grid cells. The combined effects from all confounding variables (e.g., soil type or fires) and subgrid scale heterogeneity in precipitation are presumed to increase the variance of the productivity within the populations, but the median on the large sample size retains the direction and magnitude of change in GPP due to RVP (see Supplementary Methods 1). 


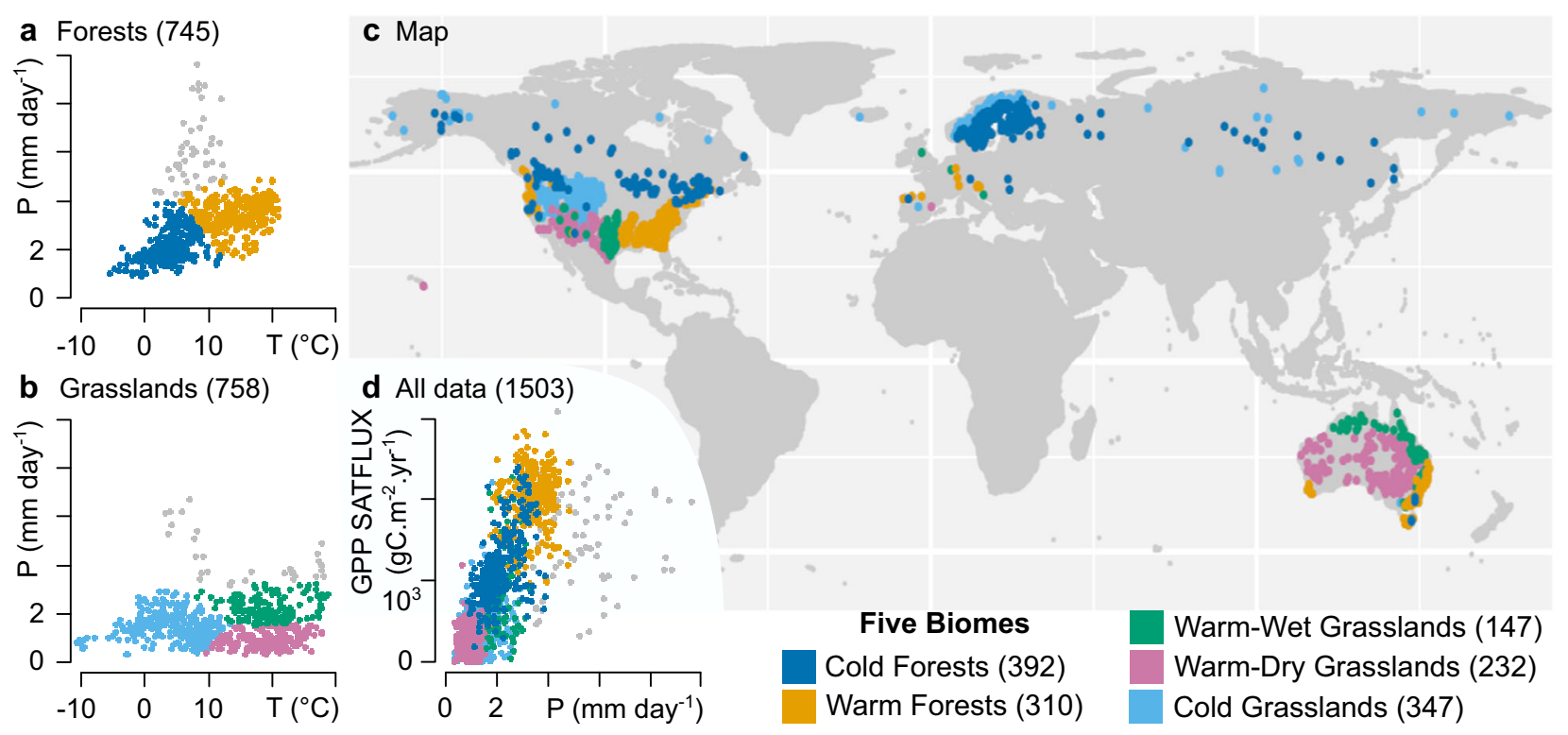

Fig. 1 Characteristics of the five biomes. a, b Relationship between long-term mean precipitation and temperature for all forested and grassland grid cells $\left(0.5^{\circ} \times 0.5^{\circ}\right)$, respectively. A cluster analysis was used to objectively separate forested and grassland sites into cold, warm, wet and dry subsets. c Map of the grid cells. $\mathbf{d}$ Relationship between GPP from SATFLUX and mean precipitation for all grid cells. For panels $\mathbf{a}, \mathbf{b}$, and $\mathbf{d}$ the number of grid cells is indicated in parenthesis and tropical grid cells are shown in gray but discarded from subsequent analysis due to the small sample size. See Supplementary Table 1 for more information.

Our results provide a clear and consistent constraint on the directional response of the productivity of terrestrial ecosystems to precipitation variance that did not emerge from previous work based on site-level studies. The development of the Unranked Gini-Index provides unequivocal evidence that intra-annual rain frequency is a more critical determinant of productivity than interannual variability for all biomes, and we observe biomespecific responses to precipitation variability. In agreement with our expectations, warm-wet grasslands and warm forests have decreased in productivity in response to higher rainfall variability, though the former is four times more sensitive (i.e., a $28 \%$ decrease in grasslands and $7 \%$ decline for forests). Conversely, cold forests show higher productivity with higher rainfall variability and especially in response to longer droughts, which likely arises from the importance of incident radiation as a primary limiting factor, but also of snow as a water source in these ecosystems. One surprising pattern that emerges is a decoupling between the way warm-dry grasslands respond to rain irregularity on an interannual scale (increase in productivity) versus intraannual scale (decline in productivity). The positive response of GPP to higher interannual variance was expected but the negative response to irregular rain within the growing season is a novel result. Particularly, short gaps between rain events emerge as more beneficial for warm-dry grasslands relative to large events that infiltrate deep into the soil. We hypothesize that more frequent rain events improve the nutrient availability and mitigate water stress through mechanisms such as foliar water uptake or reduced evapotranspiration, which could explain the unique temporal decoupling observed in this biome.

\section{Results}

Consistency between GPP products. We recognize that a significant source of uncertainty in this analysis exists from the derivation of GPP from various ecosystem models and/or satellite retrievals. We therefore chose to conduct the analysis on three products that were derived independently. These products share results with consistent direction and magnitude of change for all biomes except in cold grasslands (Fig. 3). The absolute maximum percentage of change in GPP for grasslands due to intra-annual variability ( $\mathrm{UGi}, \alpha$, or $f_{\text {dry }}$ ) ranges from 17 to $28 \%$, while forests are 3-4 times less sensitive ( $\sim 7 \%$ of change). Interannual variability $(\mathrm{CV})$ has a lesser impact than intra-annual RVPs, with a maximum of $8-12 \%$ of change for grasslands and $3 \%$ change for forests.

FLUXCOM shows a sensitivity in the response of productivity to UGi that is 4-5 times lower compared to the other two products. On average for the three grasslands, the absolute change in GPP to UGi for FLUXCOM is $4 \pm 2 \%$ (1 standard deviation), compared to $23 \pm 11 \%$ for SATFLUX and $17 \pm 5 \%$ for VPM. FLUXCOM is the only product that directly assimilates precipitation to improve GPP estimates, and we hypothesize that it leads to a reduced sensitivity to UGi because this metric is correlated to mean annual precipitation that was itself fixed in the pairing method (Supplementary Figs. 5a, 8b). While the results from all the GPP products are presented in Fig. 3, the discussion about rainfall frequency will only focus on the results from SATFLUX and VPM. More generally, we only discuss results that were common in at least two GPP products.

Cold biomes. Cold forests yield higher productivity with higher rainfall variability on both intra-annual (drier days, more irregular rain, and heavier events) and interannual scale (more extreme drought and wet years). The fraction of dry days has the largest impact on productivity, with an increase of 7\% in GPP, compared to an increase of only $2 \%$ from higher interannual variability. The maximum difference of temperature between two pairs has been set to $1.5^{\circ} \mathrm{C}$ (see "Methods" section), and cold forests are the only biome where the sensitivity to temperature is high enough that variations in temperature within this threshold had an impact on productivity similar to the RVPs (Supplementary Fig. 5b). For the cold grasslands, no consistent patterns emerged between the GPP products and we therefore draw no conclusions on how rainfall variance influences this biome.

Warm biomes. In contrast to the cold forests, the productivity of warm forests and warm-wet grasslands decreases with higher 

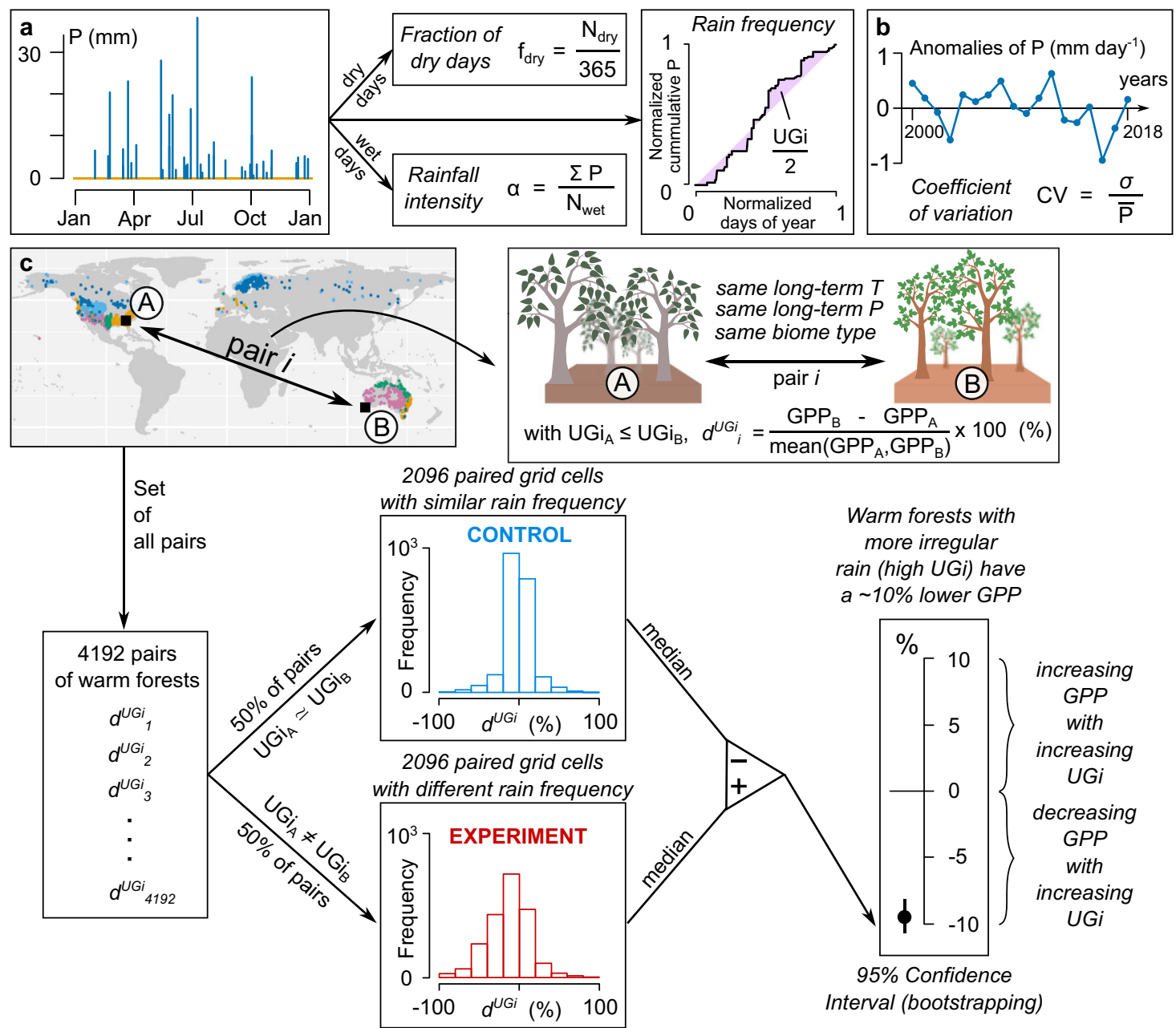

Fig. 2 Rainfall variability parameters and pairing method. a Three intra-annual rainfall variability parameters $\left(\alpha, f_{\mathrm{dry}}\right.$, and UGi). b One interannual rainfall variability parameter (CV). c Pairing method illustrated with an example of the long-term impact of UGi (related to rain irregularity) on the GPP of warm forests (SATFLUX). Two grid cells A and B are paired if they share same biome and climatological $P$ and $T$ values, and their percentage of difference in GPP is calculated $\left(\boldsymbol{d}^{U G i}\right)$. The set of all possible pairs of warm forests $(n=4192)$ is divided into a control (similar UGi within each pair) and experiment (different UGi within each pair) population to compare their median value of $\boldsymbol{d}^{\text {UGi }}$ (bottom right). This procedure was repeated for all rainfall parameters, all biomes and all GPP products to generate Fig. 3.

rainfall variability on both intra-annual and interannual scales. UGi has the largest impact on both biomes, with more irregular rain leading to a 7 and $28 \%$ decrease in the GPP of warm forests and warm-wet grasslands, respectively. In comparison, higher interannual variability only leads to a 3 and $8 \%$ decrease, respectively. While precipitation intensity has no effect on warmwet grasslands, heavier events have a slightly negative, but statistically significant, impact on warm forests $(2 \%$ of decrease in GPP).

Interestingly, productivity of warm-dry grasslands decreases with more irregular rain (by $17 \%$ ) but increases with more intense precipitation events (by 13\%) and higher year-to-year variability (by $12 \%$ ). SATFLUX is the only product that shows a low sensitivity to long-term mean annual precipitation within the pairing procedure for this biome, while the two other products are sensitive to slight increases in long-term P (Supplementary Fig. 5), certainly due to the correlation between $\mathrm{P}$ and $\mathrm{UGi}$ (Supplementary Fig. 8).

\section{Discussion}

Based on the results from previous studies, we presumed that irregularly distributed precipitation through the year (defined as
$\mathrm{UGi} \sim 1$ ) would be detrimental to ecosystems. This is confirmed in our study where temperate biomes that are neither water nor energy-limited (warm-wet grasslands, warm forests) present a significant negative response to unevenly distributed rainfall. Indeed, it has been shown that rain frequency plays an important role in the spatial distribution of these biomes ${ }^{29}$. The primary benefit of evenly distributed rainfall is that it mitigates two stressful situations: floods ${ }^{30}$ (waterlogged/hypoxic soils and loss of available precipitation through runoff) and droughts ${ }^{31}$ (waterstress eventually leading to downregulation of photosynthesis and plant senescence). While the first order pathway that links precipitation distribution to productivity is through soil moisture and root water uptake, we also note that there are other pathways that can enhance the positive response to frequent rainfall (Fig. 4). This includes, for example, evapotranspiration reduction $^{32}$ (ETR), where if precipitation regularly falls, then a decrease in vapor pressure deficit ${ }^{16}$, and cooling of the surface due to the latent heat released during evaporation or shade from the clouds $^{10}$ increases the available water. In addition, frequent rainfall may increase the potential for foliar water uptake ${ }^{33}$ (FWU), where persistent water availability on the leaf surfaces rehydrates the plant through the droplet absorption. This process has a particularly critical role in the ecohydrology of arid 
a Grasslands

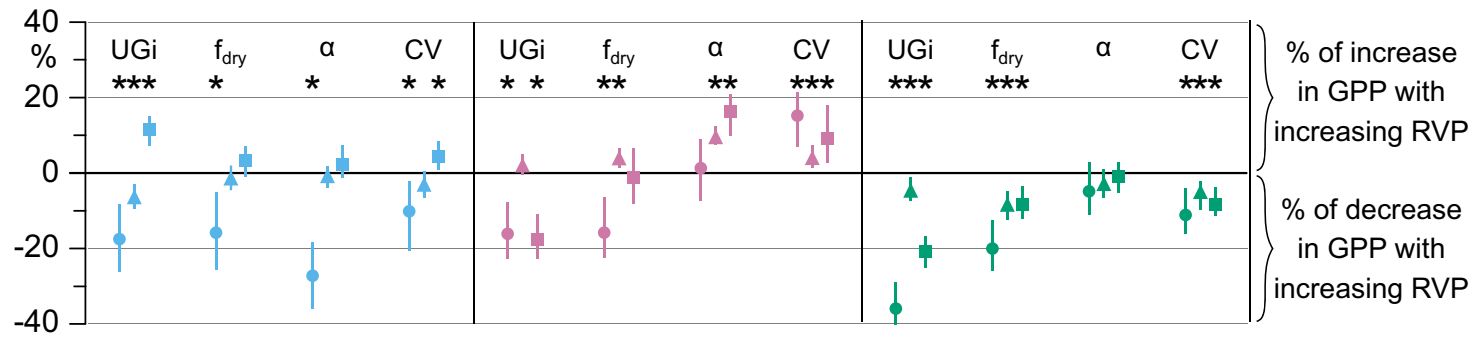

\section{b Forests}

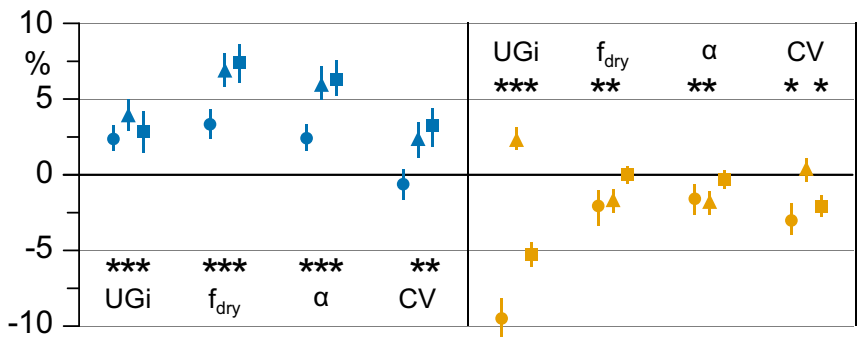

$-10$
GPP products

- SATFLUX

FLUXCOM

RS+METEO

VPM

* $p<0.05$

\section{Biomes}

Cold (3076 pairs)

Warm-Dry (2766)

Warm-Wet (1282)

Cold (6782)

Warm (4192)

Fig. 3 Long-term impact of rainfall variability on the productivity of grassland and forested biomes. $\mathbf{a}$, $\mathbf{b}$ Percentage of increase in GPP (positive values) or decrease in GPP (negative values) of the grasslands (a) and forests (b) due to higher rainfall variability, quantified by the rain irregularity (UGi), fraction of dry days $\left(f_{\text {dry }}\right)$, rain intensity $(\alpha)$ and coefficient of variation (CV). Uncertainties (95\% confidence interval) are calculated using a bootstrapping technic (Supplementary Methods 1). Circles are associated with SATFLUX data, triangles with FLUXCOM RS + METEO and squares with VPM. See Fig. 2c as an example.
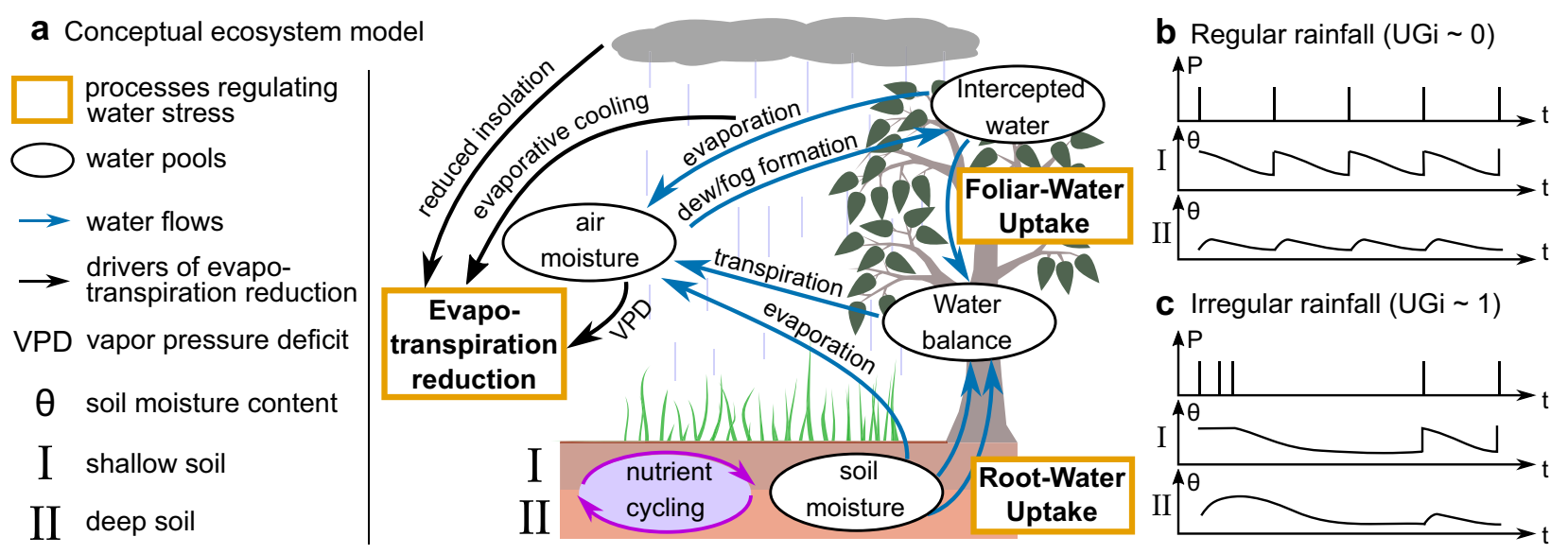

Fig. 4 Key processes relating rainfall variance to ecosystem productivity. a Water-stress mitigated by three mechanisms: root water uptake, foliar water uptake, and evapotranspiration reduction that includes energy (decrease in temperature) and water (increase in air moisture) components. Direction and magnitude of the nutrient response to rainfall variability remains poorly constrained. $\mathbf{b}, \mathbf{c}$ Idealized response of soil moisture content (divided into two layers) to regular rainfall (b) and irregular rainfall (c).

environments ${ }^{34-36}$, where dew formation typically occurs once a week $^{37}$. Furthermore, precipitation distribution influences nutrient cycling. A positive feedback exists between accumulation of organic matter (primarily driven by precipitation and temperature) and concentration of nutrients in the soil ${ }^{38}$. The balance between nutrient availability and plant nutrient uptake is however complex, and depends on microbial community composition, decomposition rates or turnover times that covary with precipitation and temperature. Inconsistent results have been found in the past between manipulative experiments that study the short-term response of an ecosystem that was put under stress, and observational studies interested in nutrient levels that represent the long-term adaptation of ecosystems to a specific climate $^{39}$. The direction and magnitude of the impact of precipitation patterns on nutrient availability therefore remain uncertain. Future studies could benefit from adopting a similar approach as used here to isolate how nutrient availability is influenced by precipitation variance.

On the contrary, we see a clear preference for higher rain variability in cold forests which arises because the accumulation of snow and its incremental melting during the spring is a more critical determinant of water availability than the evenness to which precipitation is delivered through the year ${ }^{40}$. Because these ecosystems are energy-limited, cold forests primarily benefit from more insolation (higher $f_{\text {dry }}$ ) and warmer temperatures to improve their productivity (Supplementary Fig. 5). This result is not reproduced for the cold grasslands that have a lower mean annual precipitation and are therefore more water-limited 
(Supplementary Table 1). The large discrepancies between GPP products for this biome might originate from the pooling of different land cover types, such as Shrublands or Savannahs, that have disparate plant functional responses (Supplementary Table 1). Another possible explanation is the inability of satellite data-driven models to capture productivity anomalies from these low canopy ecosystems, which often have snow cover that influences reflectance estimates of productivity.

In general, interannual and intra-annual rainfall variability are correlated $^{41}$ (Supplementary Fig. 7a) as drought years are associated with poorly distributed rainfall (Supplementary Fig. 8), and biomes typically respond in the same direction to changes on either timescale. It can be presumed that climate change would, in fact, increase the variance of rainfall on both timescales and ecosystems would have a predictable response. However, warmdry grasslands displayed opposing responses to an increase in UGi (loss of productivity with irregular rain) and increase in CV (gain in productivity with more extreme years). The preference of xeric ecosystems for higher interannual variability has previously been observed ${ }^{17,21}$, and explained through the mechanism that during years with high rainfall, water will infiltrate the soil deeper, mitigating evaporation losses, and therefore increasing the soil water availability over months or even years ${ }^{23}$. The asymmetric gain in GPP during pluvial years relative to the reduction during dry years has been well-documented, and explains the high level of resilience of xeric environments to water stress ${ }^{42}$. While the positive impact of heavier events (high $\alpha$ ) on warm-dry grasslands supports the conceptual model based on soil moisture fluctuations, the negative impact of irregularly spaced precipitation events points to additional mechanisms not directly associated with deep rainfall infiltration, such as ETR or FWU. In other words, large gaps between rainfall events lead to a decrease of moisture available on the canopy or soil surfaces, which, in turn, increases VPD and drives evaporative water loss. Because these processes occurring at the leaf surface or within the canopy are known to be poorly represented in models and neglected in rainfall manipulation experiments, they have not previously been considered as critical pathways by which rainfall variability influences productivity. Additionally, nutrient availability has been observed to decrease with increasing aridity in drylands based on a long-term observational study ${ }^{43}$, and less frequent events might negatively affect the nutrient cycling. We hypothesize that the combined effects of all these secondary processes match the benefit of a higher deep soil moisture content from larger irregular rainfalls (Fig. 4c). This hypothesis is supported by the results of a previous study that found a negative impact of less frequent events on dry shrublands ${ }^{13}$. However, their discussion was based on the difference in plant functional traits between grasslands and shrublands (rooting depths), and the existence of an intermediate rain frequency to reach optimum soil moisture levels, depending on the plant and soil type. The decoupled response of xeric grasslands to intra-annual and interannual rain frequency illustrates how the resilience of these ecosystems may emerge from their capacity to optimize the limited water pools either during periods of high interannual variance, when the soil moisture mechanism is dominant, or during periods of evenly distributed precipitation events. This contrasts with the other biomes, where dry years are associated with higher water stress because decrease in rainfall frequency leads to an overall weaker resilience to drought.

It is expected that there will be a shift towards larger and more infrequent rainfall events with warming. Our results suggest with high confidence that boreal forests will respond positively to this change, and mesic ecosystems will be put under higher stress. Xeric grasslands will have to rely more on the root water-uptake pathway and be deprived of the previously mentioned secondary pathways that are possibly crucial to mitigate water stress. The response of energy-limited grasslands, savannahs, and shrublands remains uncertain. With the exception of the boreal forests, these responses would act in opposition, and with a similar absolute magnitude, to the increase in productivity from $\mathrm{CO}_{2}$ fertilization effect. Current projections of how much the strength of the terrestrial carbon feedback will increase in response to warming and higher $\mathrm{CO}_{2}$ may be significantly affected by the dynamic physical response of precipitation to warming, and the ecological processes that emerge in response to these changes, as described in this study.

\section{Methods}

Land cover type. We classify biomes using the Moderate Resolution Imaging Spectroradiometer (MODIS) Land Cover Type Product (MCD12Q1, $500 \mathrm{~m}$ resolution, 2001-2018). The total of 17 classes from the International

Geosphere-Biosphere Program (IGBP) are merged into four generic classes: forests (includes deciduous, evergreen, mixed, and woody savannahs), grasslands (includes shrublands and savannahs), croplands (includes urban and mosaic) and "other" (remaining classes). Area-averaged land cover type for each $0.5^{\circ} \times 0.5^{\circ}$ grid is estimated from this data. Cells with more than $5 \%$ croplands are discarded. Only cells with more than $50 \%$ forests or $50 \%$ grasslands are considered, and they must contain at least one weather station with long-term daily precipitation. This strict condition explains why the Southern hemisphere is absent from the analysis (at the exception of Australia), as well as most of Asia.

Gross primary production. We use three global monthly gridded GPP datasets at a $0.5^{\circ}$ spatial resolution. For each product, only long-term (15-18 years) GPP average for each grid cell are analyzed. The first product is SAFLUX ${ }^{26}$, with data available from 2001 to 2018. It is a light-use efficiency model trained using in situ eddy covariance measurements (FLUXNET), and based on MCD43 surface reflectance from MODIS and Solar induced chlorophyll Fluorescence from GOME-2. The second product is FLUXCOM RS + METEO $^{27}$ that upscales FLUXNET observations using a machine learning method and uses a combination of MODIS and gridded meteorological products to estimate fluxes from 2001 to 2015 . The last product is the Vegetation Photosynthesis Model (VPM GPP V20). It is a light-use efficiency model similar to SATFLUX and can separate productivity from C3 and C4 plants ${ }^{28}$. Data are available from 2000 to 2016.

For each grid cell, a year* is first defined as 365 days centered around maximum GPP from SATFLUX of the seasonal component given by the STL package in R using a LOESS fit. This is done so southern and northern hemisphere sites can be treated the same in terms of precipitation timing.

Precipitation. We use 2597 weather stations from the Global Historical Climatology Network-daily (GHCN-daily $\left.{ }^{44}\right)$. Stations with more than three invalid years* ( $>5 \%$ missing daily $P$ values per year*) between 2001 and 2018 are discarded. For each valid year*, mean $P, f_{\text {dry }}, \mathrm{UGi}$, and $\alpha$ are calculated. They are then temporally averaged for each station, and CV is calculated. All parameters are finally spatially averaged using all the RVP values calculated from each weather station within the grid cell. There are, on average, 1.7 stations per grid cell (see Supplementary Fig. 1).

Temperature. Due to a lack of data in the GHCN-daily temperature, monthly CPC global temperatures ${ }^{45}$ from 2001 to $2018\left(0.5^{\circ} \times 0.5^{\circ}\right)$ are used for clustering of biomes and pairing of grid cells (Supplementary Fig. 2). It has no effect on our estimation of the GPP response to changing RVP (Supplementary Fig. 5b).

Biomes selection. A cluster analysis is performed for the grasslands and forests to select a subset of five biomes sharing similar long-term P \& T (Fig. 1a, b). The KMEANS package in $\mathrm{R}$ is used, and the number of clusters (three for the forests, four for the grasslands) is decided based on the $\mathrm{P} \& \mathrm{~T}$ range and the sample size required for the pairing method. Tropical biomes are discarded due to a too small sample size, and the characteristic of each biome (P, T, GPP, RVPs, and IGBP fraction) is presented in the Supplementary Table 1.

Pairing method. Details are provided in Supplementary Methods 1. A pair is defined as two grid cells sharing same biome, same long-term $\mathrm{P}(t$-test, $p>0.05)$ and their difference in long-term $\mathrm{T}$ is smaller than $1.5 \mathrm{C}$. Through this procedure, the effect of T \& P on the GPP of two paired grid cells is considerably reduced and becomes much lower than the influence of UGi (Supplementary Fig. 5). The difference of productivity within each pair $\left(d^{\mathrm{RVP}}\right.$, in \%) is denoted with a positive (resp. negative) sign if GPP is increasing (resp. decreasing) with higher RVP (UGi, $\alpha, f_{\text {dry }}$ or $\mathrm{CV}$ ). For each biome and each RVP, the entire population of pairs is equally divided into a control (similar RVP for both members of a pair) and experiment (different RVP for both members of a pair) population and the median values of each population's $d^{\mathrm{RVP}}$ are compared. Confidence intervals are calculated on the $2.5-97.5 \%$ quantile of a population created by bootstrapping of the pairing 
procedure $(N=10,000)$. Figure $2 \mathrm{c}$ provides a schematic depiction of the pairing method applied to UGi for the warm forest biome.

Unranked-Gini index. This rainfall frequency parameter is defined as twice the absolute area delimited by the 1:1 curve and the normalized cumulative precipitation curve (versus normalized time window, see Fig. 2a). This novel index is inspired by two former studies ${ }^{46,47}$, however by normalizing the precipitation we are able to compare across xeric and mesic sites, and the calculation of an absolute area (instead of a standard deviation) is similar to the Gini-Index ${ }^{7}$ (Supplementary Fig. 3a, b). Unlike the Gini-index, UGi does not require the precipitation to be ranked. The ecological information contained in the chronology of the rain events is therefore conserved, which is not the case for other common indices like the mean interval between rainfall events ${ }^{12}$, the Gini index or the wet-Gini index ${ }^{7}$. The high sensitivity of GPP to UGi relative to other indices highlights its skill as an ecohydrological rainfall parameter (Supplementary Fig. 6).

\section{Data availability}

Raw data: MODIS MCD12Q1 https://doi.org/10.5067/MODIS/MCD12C1.006; GHCN https://www.ncdc.noaa.gov/ghcnd-data-access; FLUXCOM http://www.fluxcom.org/; SATFLUX https://avdc.gsfc.nasa.gov/index.php?site $=2285291348 \mathrm{id}=54 \& \mathrm{go}=$ list\&path $=\%$ 2Fmonthly/0.5×0.5; VPM https://figshare.com/articles/Annual_GPP_at_0_5_degree/5048005; CPC ftp://ftp.cpc.ncep.noaa.gov/precip/PEOPLE/wd52ws/global_temp/. Processed data: https://figshare.com/articles/dataset/Distinct_response_of_gross_primary_productivity_in_ five_terrestrial_biomes_to_precipitation_variability/12937013.

\section{Code availability}

The algorithm used to perform the analysis presented in this article can be downloaded at https://figshare.com/articles/dataset/Distinct_response_of_gross_primary_productivity_in_ five terrestrial biomes to precipitation_variability/12937013.

Received: 18 March 2020; Accepted: 23 September 2020; Published online: 16 October 2020

\section{References}

1. Sun, F., Roderick, M. L. \& Farquhar, G. D. Rainfall statistics, stationarity, and climate change. Proc. Natl Acad. Sci. USA 115, 2305-2310 (2018).

2. Polade, S. D., Pierce, D. W., Cayan, D. R., Gershunov, A. \& Dettinger, M. D. The key role of dry days in changing regional climate and precipitation regimes. Sci. Rep. 4, 1-8 (2014).

3. Pascale, S., Lucarini, V., Feng, X., Porporato, A. \& ul Hasson, S. Projected changes of rainfall seasonality and dry spells in a high greenhouse gas emissions scenario. Clim. Dyn. 46, 1331-1350 (2016).

4. Pendergrass, A. G., Knutti, R., Lehner, F., Deser, C. \& Sanderson, B. M. Precipitation variability increases in a warmer climate. Sci. Rep. 7, 1-9 (2017).

5. Sun, F., Roderick, M. L. \& Farquhar, G. D. Changes in the variability of global land precipitation. Geophys. Res. Lett. 39, 1-6 (2012).

6. Feng, X., Porporato, A. \& Rodriguez-Iturbe, I. Changes in rainfall seasonality in the tropics. Nat. Clim. Change 3, 811-815 (2013).

7. Rajah, K. et al. Changes to the temporal distribution of daily precipitation. Geophys. Res. Lett. 41, 8887-8894 (2014)

8. Sloat, L. L. et al. Increasing importance of precipitation variability on global livestock grazing lands. Nat. Clim. Change 8, 214-218 (2018).

9. Huxman, T. E. et al. Convergence across biomes to a common rain-use efficiency. Nature 429, 651-654 (2004).

10. Medvigy, D., Wofsy, S. C., Munger, J. W. \& Moorcroft, P. R. Responses of terrestrial ecosystems and carbon budgets to current and future environmental variability. Proc. Natl Acad. Sci. USA 107, 8275-8280 (2010).

11. Knapp, A. K. et al. Rainfall variability, carbon cycling, and plant species diversity in a mesic grassland. Science 298, 2202-2205 (2002).

12. Guan, K. et al. Continental-scale impacts of intra-seasonal rainfall variability on simulated ecosystem responses in Africa. Biogeosciences 11, 6939-6954 (2014).

13. Ross, I. et al. How do variations in the temporal distribution of rainfall events affect ecosystem fluxes in seasonally water-limited Northern Hemisphere shrublands and forests? Biogeosciences 9, 1007-1024 (2012).

14. Ray, D. K., Gerber, J. S., Macdonald, G. K. \& West, P. C. Climate variation explains a third of global crop yield variability. Nat. Commun. 6, 1-9 (2015).

15. Dawson, T. E. \& Goldsmith, G. R. The value of wet leaves. New Phytol. 219, 1156-1169 (2018)

16. Konings, A. G., Williams, A. P. \& Gentine, P. Sensitivity of grassland productivity to aridity controlled by stomatal and xylem regulation. Nat. Geosci. 10, 284-288 (2017).
17. Zeppel, M. J. B., Wilks, J. V. \& Lewis, J. D. Impacts of extreme precipitation and seasonal changes in precipitation on plants. Biogeosciences 11, 3083-3093 (2014).

18. Wilcox, K. R. et al. Asymmetric responses of primary productivity to precipitation extremes: a synthesis of grassland precipitation manipulation experiments. Glob. Change Biol. 23, 4376-4385 (2017).

19. Zhang, Y. et al. Extreme precipitation patterns and reductions of terrestrial ecosystem production across biomes. J. Geophys. Res. Biogeosci. 118, 148-157 (2013).

20. Guo, Q. et al. Spatial variations in aboveground net primary productivity along a climate gradient in Eurasian temperate grassland: effects of mean annual precipitation and its seasonal distribution. Glob. Change Biol 18, 3624-3631 (2012).

21. Gherardi, L. A. \& Sala, O. E. Effect of interannual precipitation variability on dryland productivity: a global synthesis. Glob. Change Biol 25, 269-276 (2019).

22. Ciemer, C. et al. Higher resilience to climatic disturbances in tropical vegetation exposed to more variable rainfall. Nat. Geosci. 12, 174-179 (2019).

23. Knapp, A. K. et al. Consequences of more extreme precipitation regimes for terrestrial ecosystems. Bioscience 58, 811-821 (2008).

24. Newman, E. A., Kennedy, M. C., Falk, D. A. \& McKenzie, D. Scaling and complexity in landscape ecology. Front. Ecol. Evol. 7, 293 (2019).

25. Beguería, S., Vicente-Serrano, S. M., Tomás-Burguera, M. \& Maneta, M. Bias in the variance of gridded data sets leads to misleading conclusions about changes in climate variability. Int. J. Climatol. 36, 3413-3422 (2016).

26. Joiner, J. et al. Estimation of terrestrial global gross primary production (GPP) with satellite data-driven models and eddy covariance flux data. Remote Sens. 10, 1-38 (2018).

27. Jung, M. et al. Scaling carbon fluxes from eddy covariance sites to globe: synthesis and evaluation of the FLUXCOM approach. Biogeosciences 17, 1343-1365 (2020).

28. Zhang, Y. et al. A global moderate resolution dataset of gross primary production of vegetation for 2000-2016. Sci. Data 4, 165-170 (2017).

29. D’Onofrio, D., Sweeney, L., von Hardenberg, J. \& Baudena, M. Grass and tree cover responses to intra-seasonal rainfall variability vary along a rainfall gradient in African tropical grassy biomes. Sci. Rep. 9, 1-10 (2019).

30. Zhou, W. et al. Plant waterlogging/flooding stress responses: from seed germination to maturation. Plant Physiol. Biochem. 148, 228-236 (2020).

31. McDowell, N. et al. Mechanisms of plant survival and mortality during drought: why do some plants survive while others succumb to drought? New Phytol. 178, 719-739 (2008)

32. Tolk, J. A., Howell, T. A., Steiner, J. L., Krieg, D. R. \& Schneider, A. D. Role of transpiration suppression by evaporation of intercepted water in improving irrigation efficiency. Irrig. Sci. 16, 89-95 (1995).

33. Berry, Z. C., Emery, N. C., Gotsch, S. G. \& Goldsmith, G. R. Foliar water uptake: processes, pathways, and integration into plant water budgets. Plant Cell Environ. 42, 410-423 (2019).

34. Munne-Bosch, S., Nogues, S. \& Alegre, L. Diurnal variations of photosynthesis and dew absorption by leaves in two evergreen shrubs growing in Mediterranean field conditions. New Phytol. 144, 109-119 (1999).

35. Martin, C. E. \& Von Willert, D. J. Leaf epidermal hydathodes and the ecophysiological consequences of foliar water uptake in species of Crassula from the Namib Desert in southern Africa. Plant Biol. 2, 229-242 (2000).

36. Breshears, D. D. et al. Foliar absorption of intercepted rainfall improves woody plant water status most during drought. Ecology 89, 41-47 (2008).

37. Ritter, F., Berkelhammer, M. \& Beysens, D. Dew frequency across the US from a network of in situ radiometers. Hydrol. Earth Syst. Sci. 23, 1179-1197 (2019).

38. Marschner, B. \& Kalbitz, K. Controls of bioavailability and biodegradability of dissolved organic matter in soils. Geoderma 113, 211-235 (2003).

39. Yuan, Z. Y. et al. Experimental and observational studies find contrasting responses of soil nutrients to climate change. Elife 6, 1-19 (2017).

40. Trujillo, E., Molotch, N. P., Goulden, M. L., Kelly, A. E. \& Bales, R. C. Elevation-dependent influence of snow accumulation on forest greening. Nat. Geosci. 5, 705-709 (2012).

41. Fatichi, S., Ivanov, V. Y. \& Caporali, E. Investigating interannual variability of precipitation at the global scale: Is there a connection with seasonality? J. Clim. 25, 5512-5523 (2012).

42. Knapp, A. K., Ciais, P. \& Smith, M. D. Reconciling inconsistencies in precipitation-productivity relationships: implications for climate change. New Phytol. 214, 41-47 (2017)

43. Moreno-Jiménez, E. et al. Aridity and reduced soil micronutrient availability in global drylands. Nat. Sustain. 2, 371-377 (2019).

44. Menne, M. J., Durre, I., Vose, R. S., Gleason, B. E. \& Houston, T. G. An overview of the global historical climatology network-daily database. J. Atmos. Ocean. Technol. 29, 897-910 (2012).

45. Fan, Y. \& van den Dool, H. A global monthly land surface air temperature analysis for 1948-present. J. Geophys. Res. Atmos. 113, 1-18 (2008). 
46. Monti, A. \& Venturi, G. A simple method to improve the estimation of the relationship between rainfall and crop yield. Agron. Sustain. Dev. 27, 255-260 (2007).

47. Gu, L., Pallardy, S. G., Hosman, K. P. \& Sun, Y. Impacts of precipitation variability on plant species and community water stress in a temperate deciduous forest in the central US. Agric. For. Meteorol. 217, 120-136 (2016).

\section{Acknowledgements}

This study was partially funded by grant \#1502776 (National Science Foundation) and DE-SC0020285 (Department of Energy) to M.B.

\section{Author contributions}

F.R. and M.B. conceived the study and prepared the manuscript. C.G.E. provided the GPP product. All the authors discussed the results and contributed to editing the manuscript.

\section{Competing interests}

The authors declare no competing interests.

\section{Additional information}

Supplementary information is available for this paper at https://doi.org/10.1038/s43247020-00034-1.
Correspondence and requests for materials should be addressed to F.R. or M.B.

Peer review information Primary handling editor: Heike Langenberg.

Reprints and permission information is available at http://www.nature.com/reprints

Publisher's note Springer Nature remains neutral with regard to jurisdictional claims in published maps and institutional affiliations.

(c) (i) Open Access This article is licensed under a Creative Commons Attribution 4.0 International License, which permits use, sharing, adaptation, distribution and reproduction in any medium or format, as long as you give appropriate credit to the original author(s) and the source, provide a link to the Creative Commons license, and indicate if changes were made. The images or other third party material in this article are included in the article's Creative Commons license, unless indicated otherwise in a credit line to the material. If material is not included in the article's Creative Commons license and your intended use is not permitted by statutory regulation or exceeds the permitted use, you will need to obtain permission directly from the copyright holder. To view a copy of this license, visit http://creativecommons.org/ licenses/by/4.0/.

(C) The Author(s) 2020 